\title{
Validation of blood flow partitioning in 4D phase contrast CMR measurements using lagrangian coherent structures
}

\author{
Johannes Töger ${ }^{1 *}$, Marcus Carlsson', Gustaf Söderlind², Håkan Arheden', Einar Heiberg ${ }^{1}$ \\ From 2011 SCMR/Euro CMR Joint Scientific Sessions \\ Nice, France. 3-6 February 2011
}

\section{Introduction}

Intracardiac blood flow measurements using 4D Phase Contrast CMR (4D PC-CMR) may contain useful information about cardiac pumping. Lagrangian Coherent Structures (LCS) is a new, operator-independent method which can simplify analysis by partitioning the flow into regions with different origins and destinations. Since LCS are operator-independent, they may be used to define quantitative indices of intracardiac blood flow. The partitioning has not previously been validated against particle tracing in 4D PC-CMR blood flow.

\section{Purpose}

To investigate whether Lagrangian Coherent Structures computed from 4D Phase Contrast CMR of the human heart partitions diastolic inflow blood from blood already in the left ventricle.

\section{Methods}

Eight healthy volunteers (5 male, 3 female, ages 23-63) underwent 4D PC-CMR flow measurements of the whole heart. Three-dimensional LCS surfaces were computed and automatically delineated in the left ventricle during diastole. The only parameter adjustable by the operator was the start of diastole. Particle tracing was performed to study the blood flowing into the ventricle during diastole and the blood already present in the ventricle from the previous heartbeat. LCS and particle traces were compared visually using the software Ensight (CEI, USA).

\section{Results}

In all eight subjects, a distinct LCS was found in the left ventricle during diastole. The LCS separated the inflow blood particle traces and particle traces of blood already in the ventricle in all eight subjects. The Figure shows the typical appearance of the LCS and particle traces in one healthy volunteer.

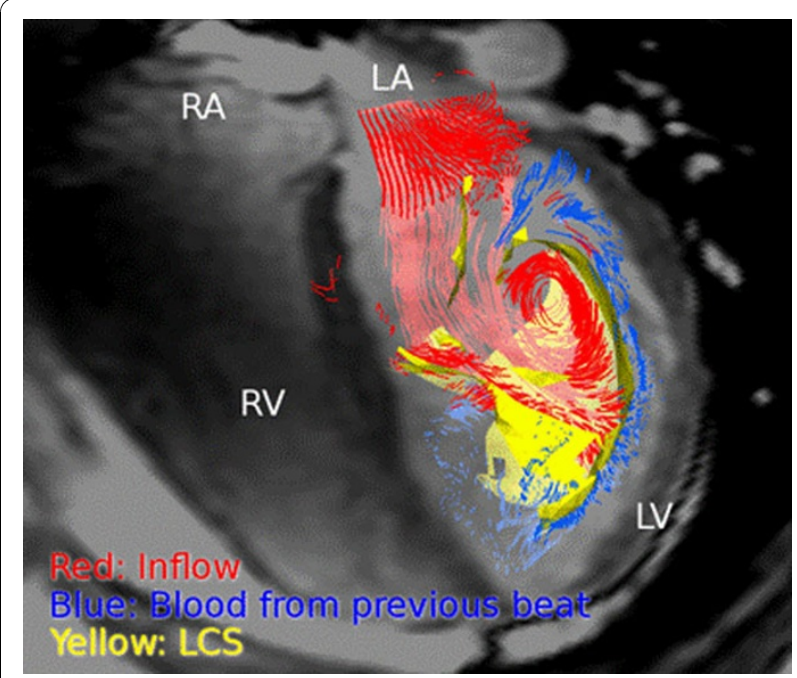

Figure 1 Lagrangian Coherent Structure (LCS, yellow) in the left ventricle of a healthy volunteer during mid-diastole. A transparent four-chamber image of the heart is shown for orientation. Red particle traces show blood flowing into the ventricle during diastole, and blue particles show blood already in the ventricle from the previous heartbeat. Note that the yellow LCS separates the blue and red particle traces. LV: Left Ventricle, RV: Right Ventricle, LA: Left Atrium, RA: Right Atrium.

TSkåne University Hospital, Lund University, Lund, Sweden

Full list of author information is available at the end of the article

(C) 2011 Töger et al; licensee BioMed Central Ltd. This is an open access article distributed under the terms of the Creative Commons 


\section{Conclusions}

Lagrangian Coherent Structures can separate 4D Phase Contrast CMR data into regions of blood with different origins. Since Lagrangian Coherent Structures are operator-independent, they have the potential to be used to define quantitative indices of intracardiac blood flow.

\section{Author details}

'Skåne University Hospital, Lund University, Lund, Sweden. ${ }^{2}$ Department of Numerical Analysis, Lund University, Lund, Sweden.

Published: 2 February 2011

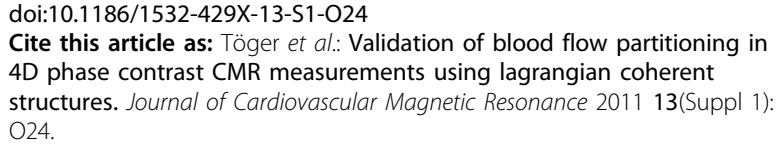

Submit your next manuscript to BioMed Central and take full advantage of:

- Convenient online submission

- Thorough peer review

- No space constraints or color figure charges

- Immediate publication on acceptance

- Inclusion in PubMed, CAS, Scopus and Google Scholar

- Research which is freely available for redistribution 